Answers given by 51 asthmatic patients to questions about their use of metered dose inhalers

\begin{tabular}{|c|c|c|}
\hline Question & Answer & $\begin{array}{c}\text { No of } \\
\text { subjects }\end{array}$ \\
\hline When do you stop using your inhaler? & $\left\{\begin{array}{l}\text { When nothing comes out of inhaler } \\
\text { When inhaler floats }\end{array}\right.$ & $\begin{array}{r}48 \\
3\end{array}$ \\
\hline $\begin{array}{l}\text { When do you ask for a repeat prescription } \\
\text { of your inhaler? }\end{array}$ & $\left\{\begin{array}{l}\text { When inhaler completely empty } \\
\text { When inhaler nearly empty } \\
\text { When reserve inhaler started }\end{array}\right.$ & $\begin{array}{r}9 \\
28 \\
14\end{array}$ \\
\hline $\begin{array}{l}\text { Have you ever found yourself without an inhaler? } \\
\text { If so, what were the consequences? }\end{array}$ & $\left\{\begin{array}{l}\text { Never without inhaler } \\
\text { No consequences when without inhaler } \\
\text { Became wheezy when without inhaler } \\
\text { Became very wheezy when without inhaler }\end{array}\right.$ & $\begin{array}{r}15 \\
3 \\
25 \\
8\end{array}$ \\
\hline Do you always have inhalers in reserve? & $\left\{\begin{array}{l}\text { Always } \\
\text { Usually } \\
\text { Often no }\end{array}\right.$ & $\begin{array}{l}10 \\
28 \\
13\end{array}$ \\
\hline Would you carry on using this inhaler? ${ }^{\star}$ & $\left\{\begin{array}{l}\text { Yes } \\
\text { No }\end{array}\right.$ & $\begin{array}{r}51 \\
0\end{array}$ \\
\hline
\end{tabular}

^Patient handed a salbutamol inhaler that was nearly empty.

\section{Comment}

Nearly all the patients in the study continued to use their inhalers after the canisters had delivered their licensed number of doses. More than half of the patients had run out of medication at some time and had consequently become wheezy. Regular inhalation of $\beta$ agonists desensitises the $\beta$ receptors of the airways, and withdrawal of the medication (or running out of it) may provoke rebound bronchospasm after 16 hours. ${ }^{3}$ The use of one canister of a salbutamol metered dose inhaler (Ventolin) a month is associated with a mortality odds ratio of $2 \cdot 4$, and greater use of the inhaler substantially increases the odds ratio. ${ }^{4}$ This may be because greater use of such an inhaler increases airway desensitisation and increases the chance of running out of medication, increasing the probability of rebound bronchospasm.

Manufacturers of metered dose inhalers are aware of this flaw, and Glaxo stated in a patent for a counter mechanism for inhalers: "the patient cannot determine the amount of medicament in the aerosol container.... This could mean that the patient, possibly suffering from severe bronchospasm and needing a dose of medicament, will find that the aerosol container will not dispense a dose because its contents have already been exhausted."s

We conclude that aerosol metered dose inhalers give insufficient information about the drug remaining in the inhaler and are therefore unsafe. A counter mechanism would rectify the problem.

1 Pearce N, Crane C, Burgess R, Jackson R, Beasley R. Beta agonists and asthma mortality: deja vu. Clin Exp Allergy 1991;21:401-10.

2 Buchanan N. Childhood asthma: what it is and what you can do. London: Piatkus, 1987:73.

3 Vathenen AS, Knox AJ, Higgins BG, Britton JR, Tattersfield AE. Rebound increase in bronchial responsiveness after treatment with inhaled terbutaline. Lancet 1988;i:554-8.

4 Spitzer WO, Suissa S, Ernst P, Horwitz RI, Habrick B, Cockcroft D, et al. The use of $\beta$-agonists and the risk of death and near death from asthma. $N$ Engl f Med 1992;326:501-6.

5 Rand PK, Osterweil CA, Newell RE, inventors. Glaxo Group, assignee. Indicating Device. US patent 4,817,822. 1989 Apr 4.

(Accepted 24 fune 1993)

\title{
Smoking and periductal mastitis
}

\section{N J Bundred, M S Dover, Nedra Aluwihare, E B Faragher, J M Morrison}

Departments of Surgery and Histopathology, Selly Oak Hospital, Birmingham B29 6JD

N J Bundred, senior lecturer in surgery

MS Dover, registrar in surgery

Nedra Aluwihare, registrar in histopathology

J M Morrison, consultant surgeon

\section{Department of Medical Statistics, University Hospital of South Manchester, Manchester M20 8LR E B Faragher, medical statistician}

\section{Correspondence to:}

Mr N J Bundred, University Hospital of South

Manchester, Manchester M20 8LR.

BMF 1993;307:772-3
Periductal mastitis and duct ectasia are well recognised, ${ }^{12}$ presenting either with acute inflammation of the breast or with chronic breast symptoms such as nipple discharge. The acute inflammatory changes seen in younger women are probably due to periductal inflammation (periductal mastitis) without duct dilatation whereas the chronic symptoms seen in older women are probably due to duct dilatation (duct ectasia) with minimal inflammation. As recurrent breast abscesses are commoner in smokers, we investigated the association between smoking and either periductal mastitis or duct ectasia in patients with a histological diagnosis.

\section{Patients, methods, and results}

Between 1981 and 1990, 71 women were identified with a histological diagnosis of periductal mastitis or duct ectasia (cases). Their clinical presentation, use of oral contraceptives, and smoking habits were recorded. They were designated as non-smokers, light smokers (1-10 cigarettes/day), or heavy smokers (11-40 cigarettes/day).

Two age matched controls were selected for each case from women who underwent surgery for a benign non-breast condition during the same year as the cases (varicose vein removal or cholecystectomy (49), gynaecological procedure (27), otorhinolaryngological procedure (23), skin biopsy (33), and dental procedure (10)). Smoking habits were available for all women but details of oral contraceptive use were unobtainable in 32 controls.

The histopathological specimens from all cases were reviewed, and the degree of periductal inflammation and duct dilatation was graded using a previously described method. ${ }^{2}$ Analysis was based on $\chi^{2}$ and Student's $t$ tests, with analysis of variance and conditional logistic regression.

The mean age of both cases and controls was 43.3 years (range 19-80). The 48 cases with acute symptoms were significantly younger (mean age 40 (SD 13)) than the 23 with chronic disease (47 (14); $t=2 \cdot 06, \mathrm{p}=0.043)$. The cases were significantly more likely to be heavy smokers than the controls $(37(52 \%)$ v $24(17 \%)$ heavy smokers, $11(15 \%) v 22(16 \%)$ light smokers, and $23(33 \%) v 96(67 \%)$ non-smokers, respectively; $\mathrm{p}<0.001$ ). Of all factors considered, smoking emerged as the only significant risk factor for periductal mastitis or duct ectasia, with a relative risk of $6.2(95 \%$ confidence interval 2.9 to 13.4$)$. Eleven patients had recurrent disease after surgery, of whom 10 were heavy smokers and one a non-smoker.

Smoking and degree of histological inflammation in 71 patients with periductal mastitis or duct ectasia. Values are numbers (percentages) of patients

\begin{tabular}{lrcc}
\hline & \multicolumn{3}{c}{ Histological inflammation } \\
\cline { 2 - 4 } & Acute & Moderate & Chronic \\
\hline Smokers $(n=48)$ & $11(23)$ & $18(37)$ & $19(40)$ \\
Non-smokers $(n=23)$ & $3(11)$ & $3(11)$ & $17(74)$ \\
\hline
\end{tabular}

$\chi^{2}=7 \cdot 5, \mathrm{df}=2, \mathrm{p}=0.023$

Smoking correlated significantly with the degree of periductal inflammation $\left(\chi^{2}=7 \cdot 5, p=0.023\right)$ (table). Duct ectasia was not associated with smoking but was inversely related to the degree of periductal inflammation $(p<0.05)$ and increased with age (mean age of patients with no dilatation 37 (9), with some dilatation 38 (12), and much dilatation 47 (14); $\mathrm{F}(2,67)=5 \cdot 022, \mathrm{p}=0 \cdot 009)$.

\section{Comment}

Histologists have always considered periductal mastitis and duct ectasia to be a single disease. ${ }^{1}$ 
Clinicians have recently questioned this theory because of the different age ranges of women with the two conditions.

In our study not only was smoking twice as frequent as the local and national age matched expected frequency ${ }^{5}$ but the number of cigarettes smoked was increased in patients. Heavy smoking increases the risk of women developing periductal mastitis, but other factors may also have a role. Women with periductal mastitis should be warned that continued smoking may lead to recurrent mammary sepsis.

The close correlation between smoking and the degree of periductal inflammation suggests that smoking is directly implicated in the pathogenesis of periductal mastitis. The finding that increasing age rather than smoking was related to duct dilatation seems to confirm clinicians' view that periductal mastitis and duct ectasia are two separate diseases. Clearly the nomenclature of these diseases needs clarification to emphasise their different aetiologies.

1 Thomas WG, Williamson RCN, Davies JD, Webb J. The clinical syndrome of mammary duct ectasia. $\mathrm{Br} \mathcal{F}$ Surg 1982;69:423-5.

2 Dixon JMJ, Anderson TJ, Lumsden AB, Elton R, Roberts HM, Forrest PM Mammary duct ectasia. Brf Surg 1985;70:601-3.

3 Bundred NJ, Dover MS, Coley S, Morrison JM. Breast abscesses and cigarette smoking. Br f Surg 1992;79:58-9.

4 Schaffer P, Furrer G, Mermillod B. An association of cigarette smoking with recurrent subareolar breast abscesses. Int $\mathcal{F}$ Epidemiol 1988;17:810-3.

5 South Birmingham Health Authority. Annual public health report 1990. Canterbury: Parker, 1990.

(Accepted 25 fune 1993)

\section{Colourings, flavourings, and sugars in children's medicines in India}

\author{
M L Kulkarni, C Sureshkumar, \\ V Venkataramana
}

Department of Paediatrics, J J M Medical College, Davangere- 577 004, Karnataka, India M L Kulkarni, professor C Sureshkumar, resident V Venkataramana, resident

Correspondence to: Professor Kulkarni.

$B M \mp$ 1993;307:773

Numbers of liquid paediatric medicines containing alcohol, flavouring, and various bases and colourings $(n=499)$

\begin{tabular}{lc}
\hline & $\begin{array}{c}\text { No of } \\
\text { medicines }\end{array}$ \\
\hline Alcohol $^{\star}$ & 53 \\
Flavouring & 11 \\
Base: & \\
Syrup & 211 \\
Sorbitol & 25 \\
Aqueous & 14 \\
Dry syrup & 30 \\
Other & 9 \\
Not mentioned & 210 \\
Colouring:t & \\
Sunset yellow FCF & 91 \\
Caramel & 83 \\
Amaranth & 72 \\
Tartrazine & 51 \\
Erythrosine & 43 \\
Ponceau 4R & 37 \\
Carmoisine & 22 \\
Brilliant blue FCF & 14 \\
Other & 9 \\
Not mentioned & 138 \\
\hline
\end{tabular}

*Range $2 \cdot 3 \%-20 \%$.

†More than one colouring was used in some products.
Most liquid medicines are for children and are usually coloured, flavoured, and sweetened with various additives. The complex role of these additives in producing unwanted effects is generally not well appreciated and often ignored. Despite awareness among the public and doctors and cooperation from pharmaceutical companies developed countries still face the health hazards due to these agents. ${ }^{2}$ The position might be worse in a developing country such as India, where lack of awareness and lax regulations give a free hand to pharmaceutical companies. We therefore examined paediatric liquid preparations for their content of alcohol, sugars, flavourings, and colourings.

\section{Methods and results}

We surveyed all paediatric liquid preparations stocked in nine pharmacies randomly selected from 86 in Davangere, a south Indian town. We scanned the label and the insert giving prescribing information. Ayurvedic (herbal) preparations, which are occasionally found in such pharmacies, were excluded.

We studied 499 products, of which 176 were tonics, 142 cough syrups, 64 antibiotics, 48 analgesics or antipyretics, 23 antiemetics or antidiarrhoeals, eight antiamoebics, and 38 miscellaneous products. Overall, 401 products were manufactured by 142 national pharmaceutical companies and 98 by 30 regional (three to five state) companies. The study thus largely reflects what is happening in India.

Twenty three cough syrups, 23 tonics, five antipyretics, and two miscellaneous preparations contained alcohol, ranging from $2 \cdot 8 \%$ to $20 \%, 2 \cdot 3 \%$ to $14.3 \%, 8.95 \%$ to $10 \%$, and $2 \cdot 3 \%$ to $4 \%$ respectively. The table shows the numbers of products containing additives. Sixty three products did not mention any additives or specified that the product was free of them.

Twenty companies were randomly selected from the 172 to assess how many of their paediatric oral drugs were liquids. Of the 148 preparations, 32 were tablets and 116 liquids.

\section{Comment}

Additives used in medicines are generally considered to be inert, and their adverse reactions are often erroneously attributed to the active ingredients. Studies have proved, however, that the reactions caused by additives may not be trivial ${ }^{2}$ - for example, $5-10 \%$ of allergic reactions in asthmatic patients occur with sulphites and $0-40 \%$ with tartrazine. ${ }^{3}$ Many countries have therefore made it compulsory to include full details of the additives on the label. ${ }^{2}$ Our study shows that numerous products did not contain enough information about the additives used or claimed that they were absent, thus making it difficult for susceptible people to avoid additives.

In the United States more than 700 medicines contain alcohol. ${ }^{4}$ Because of toxicity and drug interactions the American Academy of Pediatrics has recommended against the use of alcohol in children's medicines. Many pharmaceutical companies in developed countries have consequently taken steps to reduce or remove alcohol from their products. ${ }^{4}$ The high alcohol content in all categories of children's medicines marketed in India is worrying.

The evidence relating sucrose in medicines to dental caries led to the development of sugar free formulations in Western countries, ${ }^{3}$ and nearly a quarter of British pharmacists sell only sugar free medicines when available. ${ }^{5}$ In contrast, we found that $82 \%$ of preparations had a syrupy base and few listed the amount of sugar.

Reports of adverse effects resulted in less frequent use of colourings in medicines. In two studies, from Britain $^{2}$ and Switzerland, ${ }^{3}$ only a quarter of formulations contained colourings, whereas in our study $72 \%$ of products contained colourings. Most of the remaining products were also coloured but did not specify which colouring had been used.

We found that less than $3 \%$ of products mentioned the flavouring used. Several chemicals are needed to produce one flavour, so isolating the culprit is impracticable-for example, synthetic strawberry requires 30 ingredients. ${ }^{1}$

In our study nearly $80 \%$ of children's oral medicines were produced as liquids, although generally tablets may be used effectively in children. Such a variety of liquid preparations adds to the economic burden of the poor and is obviously unnecessary. Strict regulations and ethical and judicious use of liquid medicines by practitioners are necessary to contain the problem of additives in medicines.

1 Kumar A, Weatherly MR, Beaman DC. Sweeteners, flavouring and dyes in antibiotic preparations. Pediatrics 1991;87:352-60.

2 Pollock I, Young E, Stoneham M, Slater N, Wilkinson JD, Warner JO. Survey of colourings and preservatives in drugs. $B M \mathcal{F} 1989 ; 299: 649-51$.

3 Kolly M, Pecoud A, Frei PC. Additives contained in drug formulations most frequently prescribed in Switzerland. Ann Allergy 1989;62:21-5.

4 American Academy of Pediatrics-Committee on Drugs. Ethanol in liquid preparations intended for children. Pediatrics 1989;73:405-7.

5 Holmes A, Davidson LE. Sugar-free medicines: a lost opportunity. Br Dent $f$ 1987;163:240-1.

(Accepted 18 fune 1993) 